\title{
Pancreatic Acinar Cell Carcinoma with Multiple Liver Metastases Effectively Treated by S-1 Chemotherapy
}

\author{
Naoki Yoshida ${ }^{1}$, Atsushi Kanno ${ }^{1}$, Atsushi Masamune ${ }^{1}$, Tatsuhide Nabeshima ${ }^{1}$, Seiji Hongo ${ }^{1}$, \\ Shin Miura ${ }^{1}$, Tetsuya Takikawa ${ }^{1}$, Shin Hamada ${ }^{1}$, Kazuhiro Kikuta ${ }^{1}$, Kiyoshi Kume ${ }^{1}$, \\ Masamichi Ueno $^{2}$ and Tooru Shimosegawa ${ }^{1}$
}

\begin{abstract}
:
A 79-year-old woman was referred for pancreatic tail cancer with multiple liver metastases. The pancreatic tail tumor was diagnosed as acinar cell carcinoma (ACC) histologically by endoscopic ultrasound-guided fine-needle aspiration. Because of multiple liver metastases, S-1 chemotherapy was administered, resulting in a partial response to chemotherapy one year later. After approximately three years, liver atrophy and esophageal varices developed. We suspected S-1 as the cause of the liver cirrhosis. S-1 cessation minimized ascites and improved the esophageal varices. Although S-1 can potentially treat ACC, we should be watchful for liver cirrhosis caused by its long-term administration.
\end{abstract}

Key words: chemotherapy, acinar, liver cirrhosis

(Intern Med 57: 3529-3535, 2018)

(DOI: 10.2169/internalmedicine.0294-17)

\section{Introduction}

Acinar cell carcinoma (ACC) is a very rare tumor, accounting for $1-2 \%$ of all pancreatic tumors (1). The definite diagnosis of ACC requires a histological examination (2). Resection is the first choice of treatment for operable ACC with tumor progression limited to the primary lesion, whereas chemotherapy is administered to patients with metastases. However, no effective chemotherapy has been established for ACC because of its rarity.

We herein report the case of a patient with onset of ACC in the pancreatic tail with multiple liver metastases effectively treated by S-1 chemotherapy and present a review of the literature.

\section{Case Report}

A 79-year-old woman presented to her local physician with chief complaints of epigastric discomfort and loss of appetite. The patient was receiving treatment with oral drugs for hypertension and diabetes. Contrast-enhanced abdominal computed tomography (CT) revealed a 4-cm mass with poor contrast enhancement and an indistinct border in the pancreatic tail and multiple masses in the liver. She was referred to our department for a closer examination and treatment (Fig. 1).

A physical examination revealed no particular abdominal abnormalities, and no findings suggestive of subcutaneous fat necrosis or polyarthralgia specific to ACC were observed. Blood biochemistry results revealed anemia with a hemoglobin level of $9.9 \mathrm{~g} / \mathrm{dL}$. The serum amylase level was $36 \mathrm{U} / \mathrm{L}$, which was within the normal range; however, the serum lipase level was markedly elevated at 2,048 U/L. Mild elevation of biliary enzymes was observed; the alkaline phosphatase (ALP) level was $441 \mathrm{U} / \mathrm{L}$ and the $\gamma$ glutamyltransferase $(\gamma$-GTP) level was $67 \mathrm{U} / \mathrm{L}$. Among tumor markers, the cancer antigen 19-9 (CA 19-9) level was mildly elevated at $52.0 \mathrm{U} / \mathrm{mL}$; however, the carcinoembryonic antigen (CEA) and $\alpha$-fetoprotein (AFP) levels were 2.4 $\mathrm{ng} / \mathrm{mL}$ and $2.7 \mathrm{ng} / \mathrm{mL}$, respectively, which were within normal ranges. Endoscopic ultrasound (EUS) revealed a hetero-

${ }^{1}$ Division of Gastroenterology, Tohoku University Graduate School of Medicine, Japan and ${ }^{2}$ Division of Internal Medicine, Tohoku Medical and Pharmaceutical University Wakabayashi Hospital, Japan

Received: October 2, 2017; Accepted: April 23, 2018; Advance Publication by J-STAGE: August 10, 2018

Correspondence to Dr. Atsushi Kanno, atsushih@med.tohoku.ac.jp 
geneous hypoechoic mass in the pancreatic tail. Ultrasound using a contrast medium revealed blood flow within the tumor (Fig. 2). EUS-fine-needle aspiration (FNA) was performed, and a histopathological examination of the aspirated sample revealed tumor cells with eosinophilic cytoplasm, relatively small oval nuclei, and a solid growth pattern. Immunohistological staining was diffusely positive for cytokeratin AE1/AE3 and positive for $\beta$-catenin in the cytoplasm and cell membrane; however, it was negative for chromogranin A and synaptophysin. Cells showed positive staining for $\alpha 1$-antichymotrypsin, trypsin, and Bcl-10, and approximately $30-40 \%$ of the cells were positive for Ki67, indicating a high proliferative capacity (Fig. 3). Based on these results, the patient was diagnosed with pancreatic ACC. The multiple masses in the liver were considered metastases of ACC.

Because distal metastasis was observed, surgery was not considered. The patient was in good general condition, and

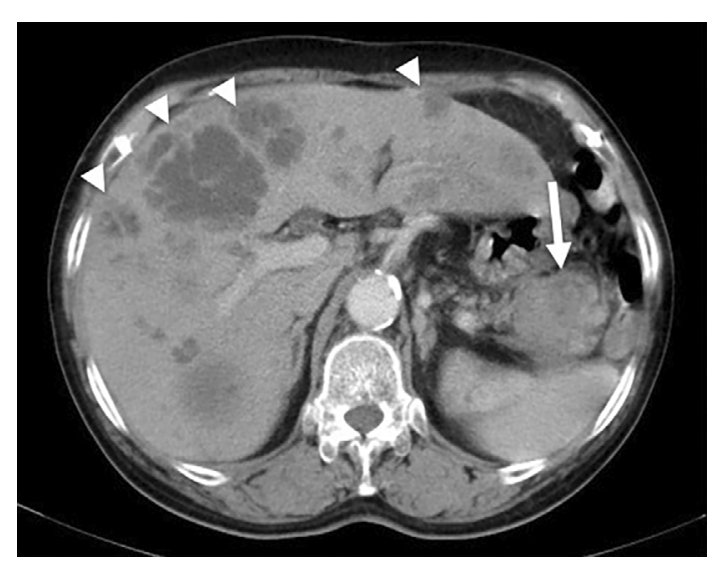

Figure 1. Contrast-enhanced abdominal CT performed at the initial examination. Multiple masses with poor contrast enhancement were observed in the liver (arrowhead), and a mass with poor contrast enhancement and an indistinct border was observed in the pancreatic tail (arrow).
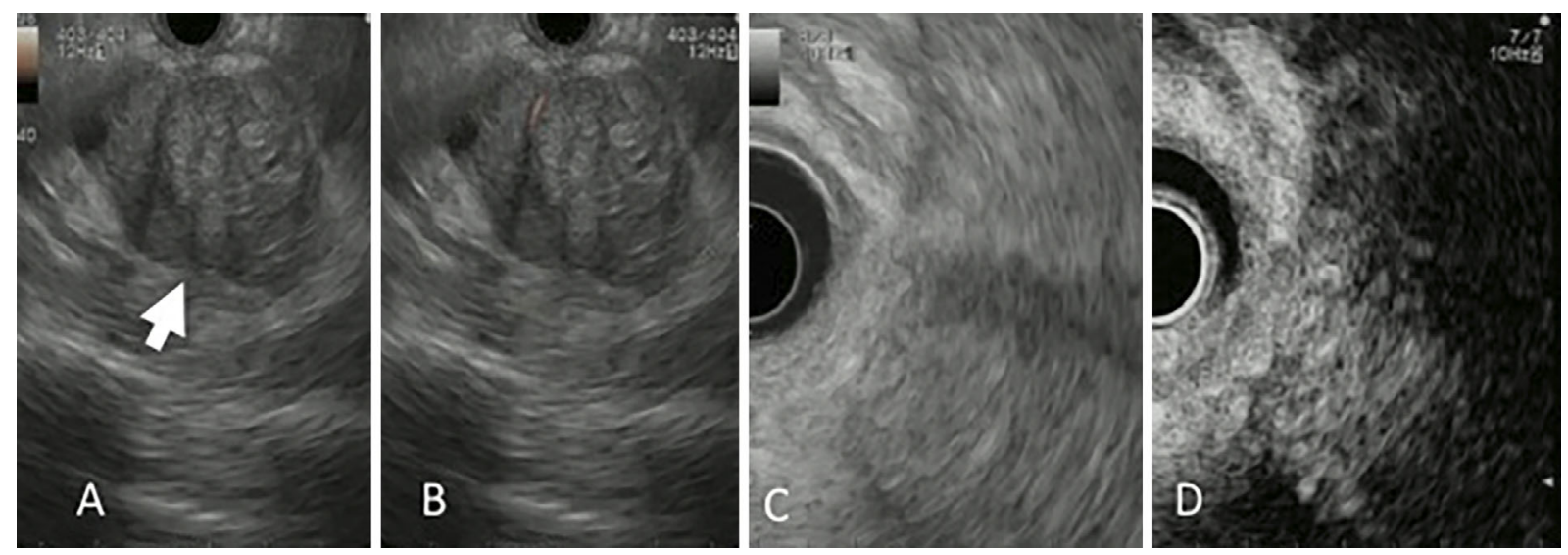

Figure 2. Endoscopic ultrasound findings. A tumor (arrow) with a relatively distinct border and heterogeneous echo pattern was observed using endoscopic ultrasound (A). Using power Doppler (B) and ultrasound contrast medium (D), we confirmed blood flow within the tumor, indicating a viable tumor. No clear cystic degeneration was observed. $\mathrm{C}$ is a referential image of contrast-enhanced image. 


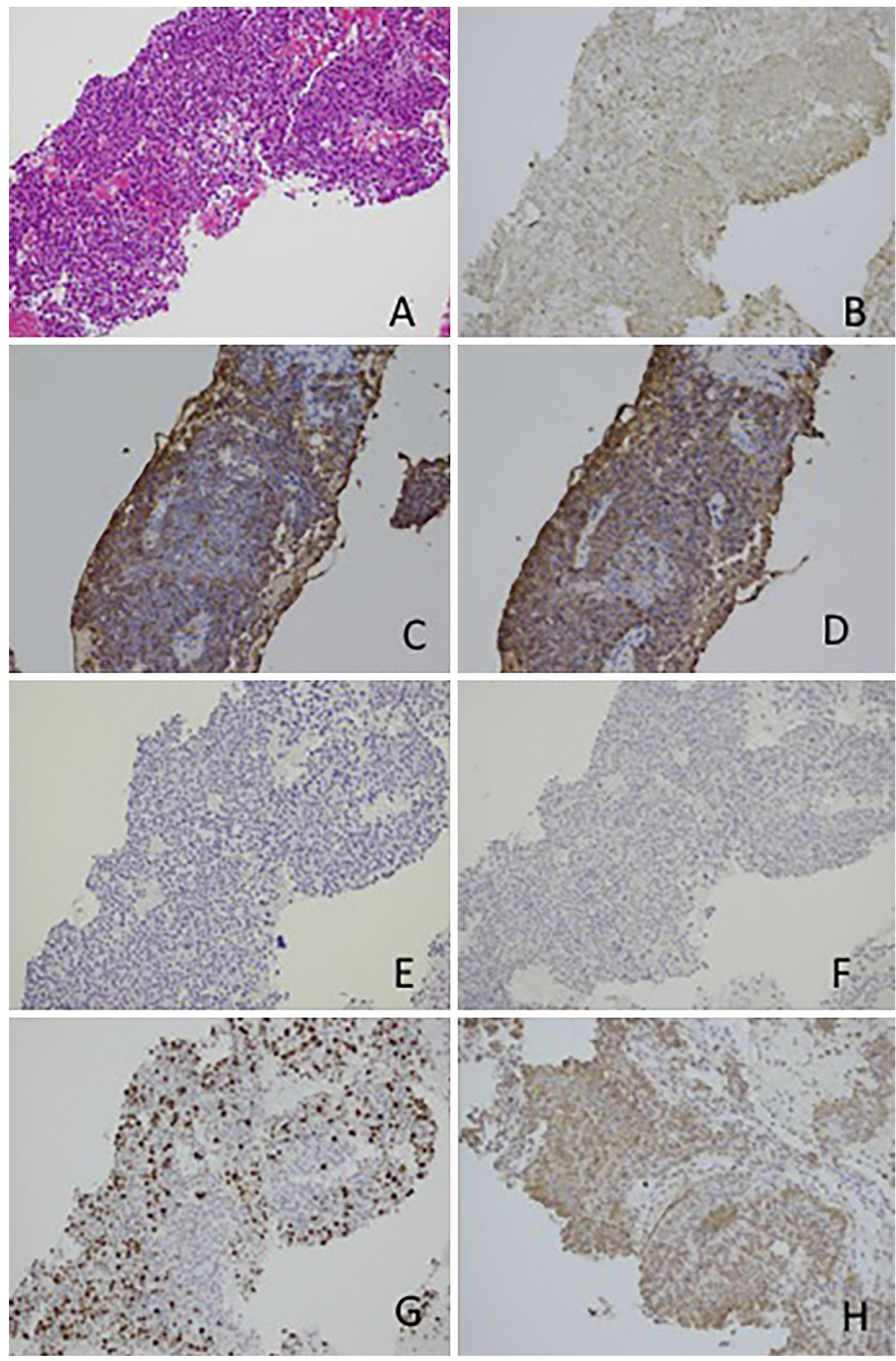

Figure 3. Histopathological findings of the endoscopic ultrasound fine-needle aspiration sample. Tumor cells with relatively small oval nuclei, eosinophilic cytoplasm, and a solid growth pattern were detected using Hematoxylin and Eosin staining. (A) Positive staining for $\alpha 1$-antichimotrypsin (B), trypsin (C), and Bcl 10 (D). Negative staining for chromogranin A and synaptophysin. (E, F) Approximately $30-40 \%$ of cells were positive for Ki67. (G) $\times 200$ magnification. Positive staining for thymidylate synthase $(\mathrm{H})$.

Elevation of tumor markers, including serum CEA, CA19-9, and Span-1, is generally not observed (3). Although our patient exhibited eosinophilia and an elevated serum lipase level, only nonspecific symptoms, including epigastric pain and loss of appetite, were observed. Abnormally high AFP levels are observed in only approximately $6 \%$ of patients with pancreatic cancer (4); however, among pancreatic tumors that are associated with elevated serum AFP levels,
$27 \%$ are ACC (5). In the present patient, an elevated AFP level was not observed.

Cystic degeneration, bleeding, and calcification often develop within the ACC tumor $(6,7)$. According to a report summarizing cases of patients with ACC, distant metastasis is observed at the initial examination in approximately $50 \%$ of patients; the majority of metastases arise in the liver $(8,9)$. The median overall survival of patients with 


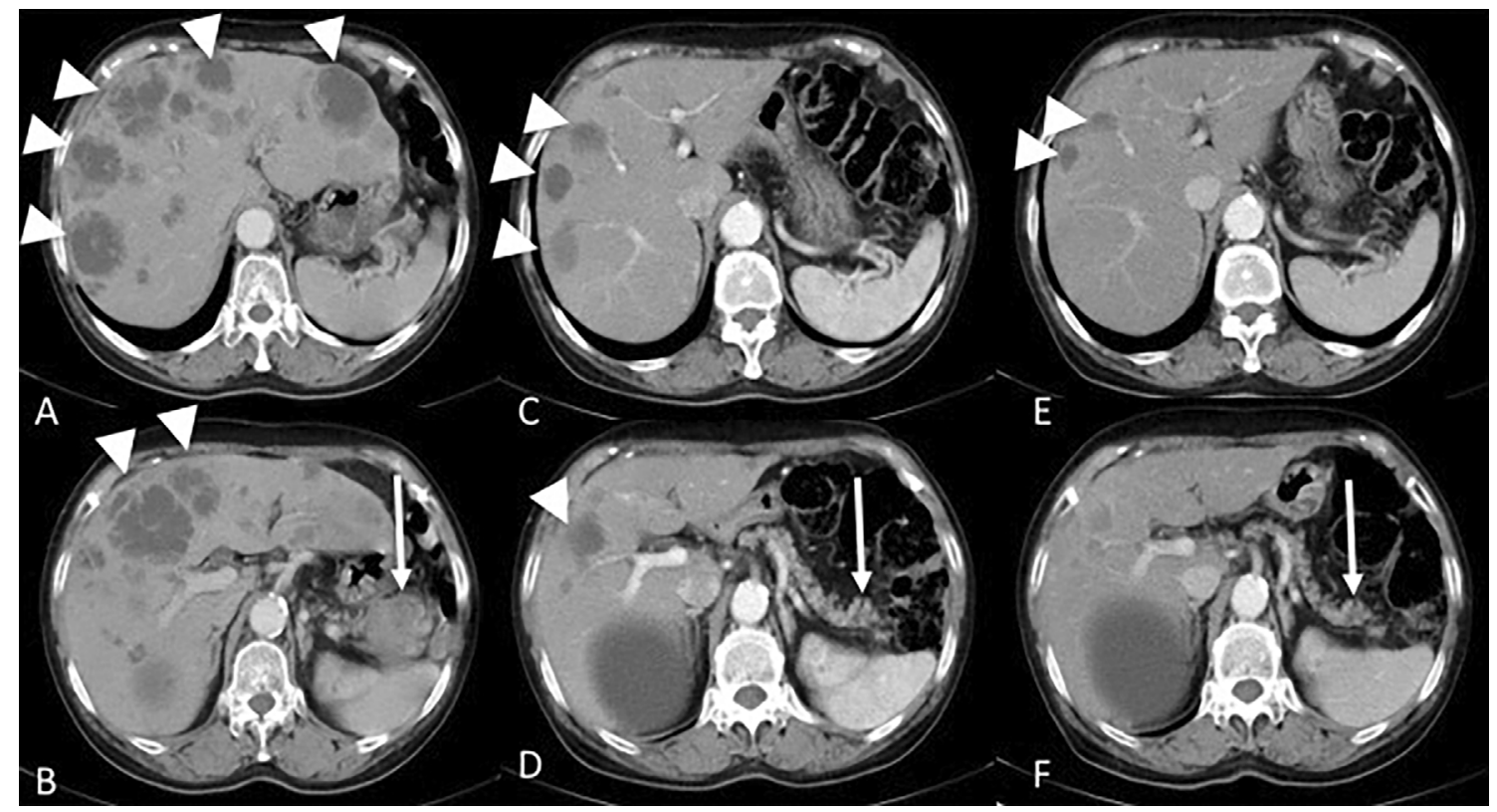

Figure 4. S-1 chemotherapy induced changes in the tumor. Prior to starting treatment (A, B), pancreatic tail tumor (arrow) and multiple liver metastases (arrowhead) were seen. Six months after treatment $(C, D)$, marked reductions in both the pancreatic tail tumor and liver metastases were seen. One year after treatment $(\mathrm{E}, \mathrm{F})$, the primary lesion had completely disappeared.
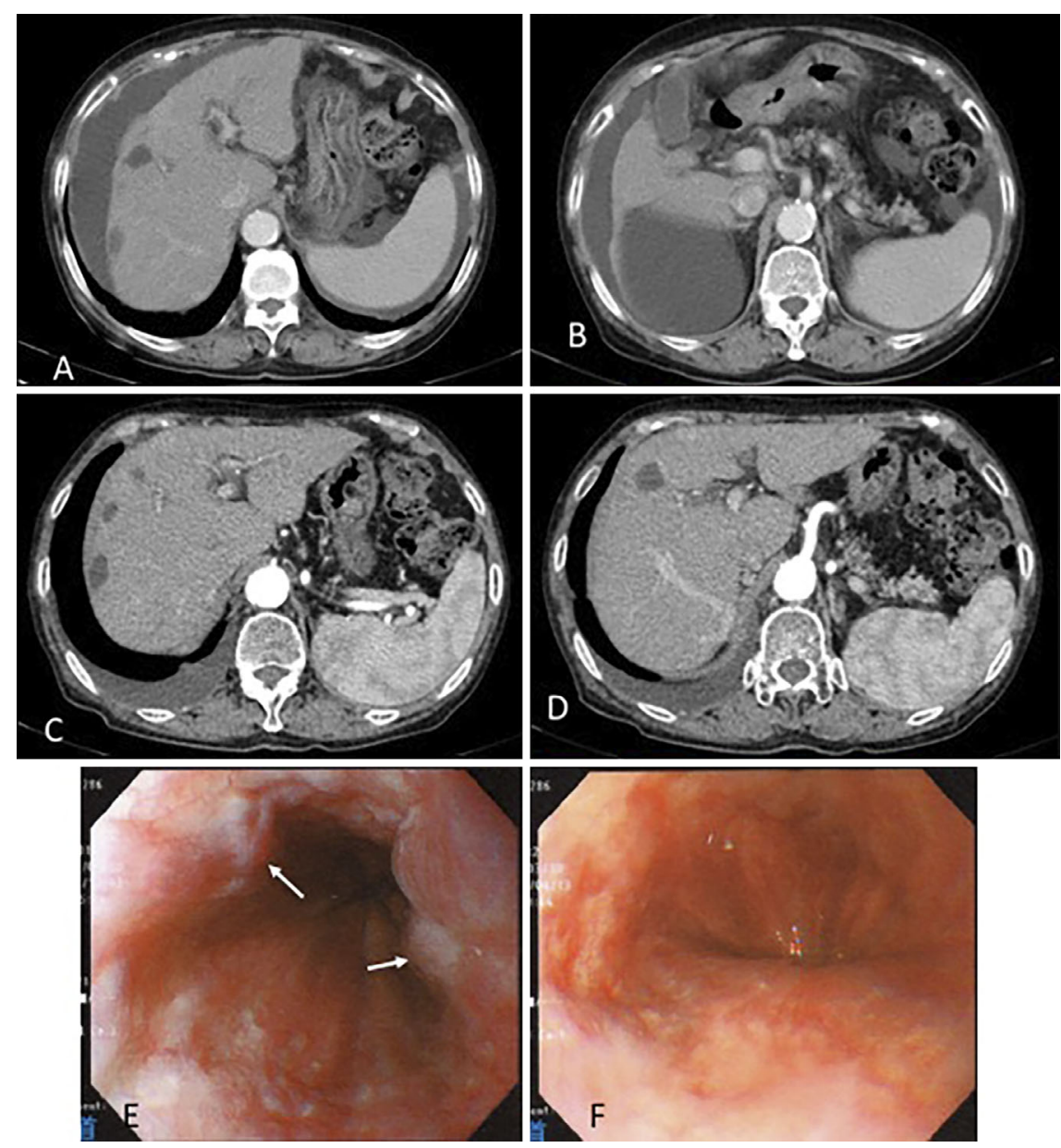

Figure 5. After three years of treatment, CT revealed increased ascites and liver atrophy (A, B). After four years of treatment, cessation of S-1 minimized the amount of ascites (C, D). After three years of treatment, upper gastrointestinal endoscopy showed varices with red color sign (arrow) in the middle and lower esophagus (E). Cessation of S-1 improved the varices after another year (F). 
The metabolism and activation of S-1/5-FU

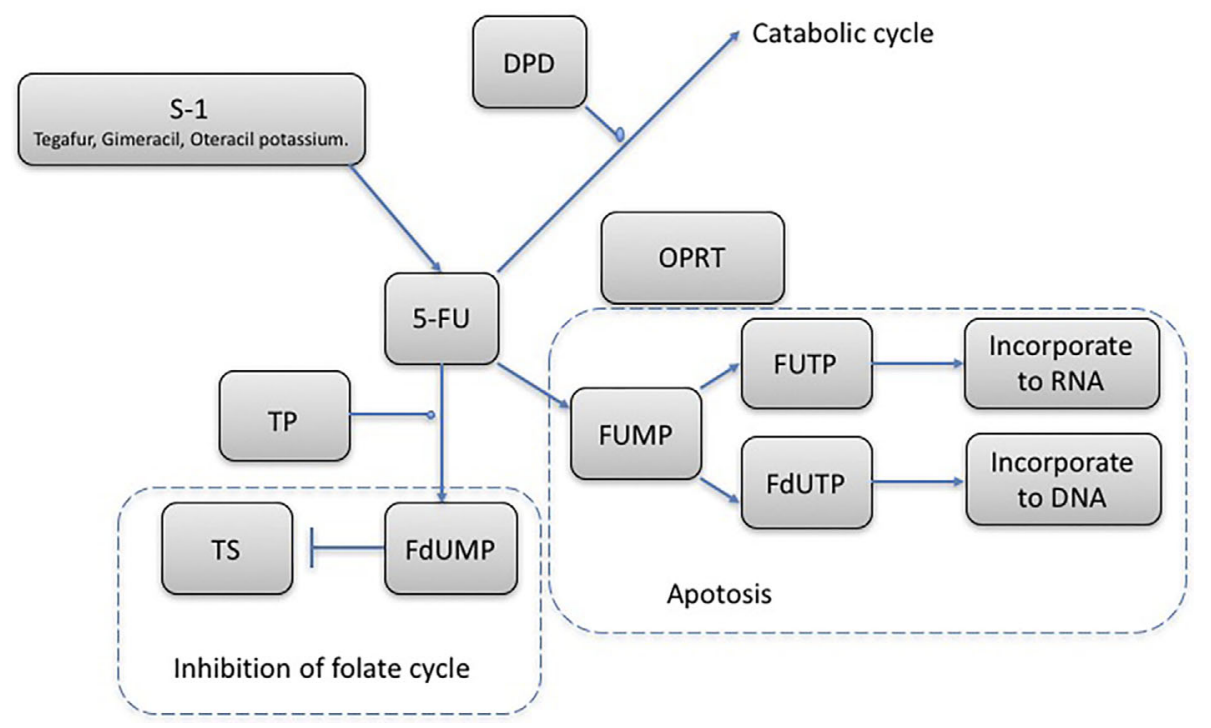

Figure 6. The main metabolic pathway and mechanistic overview of S-1/5-FU. Tegafur is a precursor to 5-FU, gimeracil inhibits the 5-FU catabolic enzyme dihydropyrimidine dehydrogenase (DPD), and oteracil potassium acts in the gastrointestinal tract primarily blocking orotate phosphoribosyltransferase (OPRT) and reducing gastrointestinal mucous membrane disorder. Thymidine phosphorylase, DPD, thymidylate synthase (TS), and OPRT are enzymes required for metabolizing and activating 5-FU. In particular, TS, a rate-limiting enzyme in the DNA synthesis pathway, is important for determining resistance to fluoropyrimidine. Fluorodeoxyuridylate, the 5-FU active metabolite, binds to TS, which inhibits new DNA synthesis and thereby exerts antitumor effects.

ACC is reported to be 18.1-33 months, which is better than that of patients with common pancreatic cancers, but poorer than that of patients with neuroendocrine tumors $(8,9-11)$.

Surgical treatment is generally selected for patients with ACC without distant metastasis. In contrast, chemotherapy is generally administered to patients with metastasis. Among the available reports on chemotherapy for ACC, some describe the use of 5-fluorouracil (5-FU), a fluorinated pyrimidine; however, reports on Japanese patients describe the use of S-1 chemotherapy (12-17). A previous report found that, among 22 patients with ACC who received chemotherapy, the majority responded to 5-FU (9), indicating that fluorinated pyrimidines are promising candidates for treating ACC. S-1 chemotherapy consists of a combination of tegafur, gimeracil, and oteracil potassium. S-1 chemotherapy for ACC is considered promising.

Although the expression of certain enzymes plays an important role in the activation of 5-FU (18) (Fig. 6), the expression of thymidylate synthase (TS) in gastric and colorectal cancers is reported to be correlated with resistance to 5-FU treatment $(19,20)$. Although several studies have examined the TS expression in pancreatic cancer, the relationship between the TS expression and the prognosis of pancreatic cancer is unclear (21-26). It has been reported that the TS expression is lower in pancreatic cancer tissue than in cancer tissues of other organs (27), and it is presumed that a low TS expression indicates resistance to fluoropyrimidine agents. To date, there have been no reports of TS immunostaining performed in ACC. In the present patient, we found a high TS expression on immunostaining (Fig. 3H), which we believe to be one of the reasons for the patient's partial response to $\mathrm{S}-1$ chemotherapy. There may be a difference between ACC and other pancreatic cancers in the expression of enzymes involved in the 5-FU metabolism; further case studies are required for a better understanding.

We encountered a case of liver cirrhosis caused by the long-term administration of S-1 for the treatment of ACC with multiple liver metastases. Liver dysfunction frequently occurs as an adverse effect of chemotherapy due to sinusoidal obstruction syndrome (28) or steatohepatitis (29). There have been no reports of an association between S-1 and liver cirrhosis except for some case reports of an association between tegafur and liver dysfunction or fibrosis in patients without any baseline liver diseases (Table) (30-35). Liver cirrhosis occurred in this case due to the continued use of S1 for anticancer therapy. The appropriate duration for continuing chemotherapy in cancer patients cannot be determined, as the criteria for withdrawing therapy have not been established. Indications for withdrawing anticancer therapy are problems with toxicity and patient refusal. It is important to stop anticancer treatment in the event of chemotherapy toxicity, and we should carefully monitor all side effects of chemotherapy. Furthermore, there is a risk of secondary carcinoma due to the long-term administration of chemo- 
Table. Previous Case Reports Concerning about Tegafur and Liver Dysfunction without Any Baseline Diseases of the Liver.

\begin{tabular}{cccccccc}
\hline $\begin{array}{c}\text { Case } \\
\text { No. }\end{array}$ & Reference & Sex & Age & Cancer & Chemotherapy & Duration & Results \\
\hline 1 & $(32)$ & F & 51 & Uterus ca & Tegafur/OK-432 & 3 weeks & Liver dysfunction \\
2 & $(33)$ & F & 38 & Breast ca & Tamoxifen/ Tegafur & 3 months & Liver cirrhosis \\
3 & $(33)$ & F & 41 & Breast ca & Tamoxifen/ Tegafur & 8 months & Liver cirrhosis \\
4 & $(34)$ & F & 76 & Colon ca & Tegafur/Uracil & 10 months & Chronic active hepatitis \\
5 & $(35)$ & M & 55 & n.a. & Tegafur/Uracil & 50 months & Hepatic fibrosis \\
6 & $(36)$ & M & 81 & Lung ca & Tegafur/Uracil & 2 weeks & Liver dysfunction \\
7 & $(37)$ & F & 74 & Breast ca & Tegafur/Uracil & 8 months & Hepatic fibrosis \\
\hline
\end{tabular}

F: female, M: male, ca: cancer, n.a.: not acquired

therapy $(36,37)$. Because $S-1$ is recommended as first-line adjuvant chemotherapy for pancreatic cancer in Japan, we present this case to draw attention to an important side effect associated with its long-term use.

In conclusion, we herein report the case of a patient with ACC with multiple liver metastases. She showed a partial response to oral S-1 chemotherapy and achieved a long-term survival without the presence of any detectable tumors. S1 chemotherapy might be useful for treating ACC patients with a high TS expression. However, physicians must be watchful for potential liver cirrhosis during its long-term use.

The authors state that they have no Conflict of Interest (COI).

\section{References}

1. Morohoshi T, Held G, Klöppel G. Exocrine pancreatic tumours and their histological classification. A study based on 167 autopsy and 97 surgical cases. Histopathology 7: 645-661, 1983.

2. La Rosa S, Adsay V, Albarello L, et al. Clinicopathologic study of 62 acinar cell carcinomas of the pancreas: insights into the morphology and immunophenotype and search for prognostic markers. Am J Surg Pathol 36: 1782-1795, 2012.

3. Kitagami H, Kondo S, Hirano S, Kawakami H, Egawa S, Tanaka M. Acinar cell carcinoma of the pancreas: clinical analysis of 115 patients from Pancreatic Cancer Registry of Japan Pancreas Society. Pancreas 35: 42-46, 2007.

4. Butturini G, Pisano M, Scarpa A, D'Onofrio M, Auriemma A, Bassi C. Aggressive approach to acinar cell carcinoma of the pancreas: a single-institution experience and a literature review. Langenbecks Arch Surg 396: 363-369, 2011.

5. Fitzgerald PJ, Fortner JG, Watson RC, et al. The value of diagnostic aids in detecting pancreas cancer. Cancer 41: 868-879, 1978.

6. Nojima T, Kojima T, Kato H, Sato T, Koito K, Nagashima K. Alpha-fetoprotein-producing acinar cell carcinoma of the pancreas. Hum Pathol 23: 828-830, 1992.

7. Raman SP, Hruban RH, Cameron JL, Wolfgang CL, Kawamoto S, Fishman EK. Acinar cell carcinoma of the pancreas: computed tomography features--a study of 15 patients. Abdom Imaging 38: 137-143, 2013.

8. Klimstra DS, Heffess CS, Oertel JE. Acinar cell carcinoma of the pancreas. A clinicopathologic study of 28 cases. Am J Surg Pathol 16: 815-837, 1992.

9. Lowery MA, Klimstra DS, Shia J, et al. Acinar cell carcinoma of the pancreas: new genetic and treatment insights into a rare malig- nancy. Oncologist 16: 1714-1720, 2011.

10. Hsu MY, Pan KT, Chu SY, Hung CF, Wu RC, Tseng JH. CT and MRI features of acinar cell carcinoma of the pancreas with pathological correlations. Clin Radiol 65: 223-229, 2010.

11. Holen KD, Klimstra DS, Hummer A, et al. Clinical characteristics and outcomes from an institutional series of acinar cell carcinoma of the pancreas and related tumors. J Clin Oncol 20: 4673-4678, 2002.

12. Webb JN. Acinar cell neoplasms of the exocrine pancreas. J Clin Pathol 30: 103-112, 1977.

13. Seth AK, Argani P, Campbell KA, et al. Acinar cell carcinoma of the pancreas: an institutional series of resected patients and review of the current literature. J Gastrointest Surg 12: 1061-1067, 2008.

14. Yamamoto T, Ohzato $H$, Fukunaga $M$, Imamura $H$, Furukawa $H$. Acinar cell carcinoma of the pancreas: a possible role of S-1 as chemotherapy for acinar cell carcinoma. A case report. JOP 13: 87-90, 2012.

15. Seki Y, Okusaka T, Ikeda M, Morizane C, Ueno H. Four cases of pancreatic acinar cell carcinoma treated with gemcitabine or S-1 as a single agent. Jpn J Clin Oncol 39: 751-755, 2009.

16. Kanemasa $Y$, Kamisawa $T$, Tabata $T$, et al. Mixed acinar-endocrine carcinoma of the pancreas treated with S-1. Clin J Gastroenterol 6: 459-464, 2013.

17. Yoneda M, Kanayama K, Imai H, Shiraishi T. Report of a case of acinar cell carcinoma with its differential diagnosis on endoscopic ultrasound-guided fine-needle aspiration cytology. J Cytol 31: 9395, 2014.

18. Asayama N, Kojima Y, Aoki T, et al. Acinar cell carcinoma of the pancreas with colon involvement. Case Rep Med 2014: 389425, 2014.

19. Sumiyoshi T, Shima $Y$, Okabayashi $T$, et al. Long-term survival following pancreatectomy and S-1 chemotherapy for pancreatic acinar cell carcinoma with peritoneal dissemination: a case report and literature review. Medicine (Baltimore) 94: e378, 2015.

20. Danenberg PV. Thymidylate synthetase-a target enzyme in cancer chemotherapy. Biochim Biophys Acta 473: 73-92, 1977.

21. Lenz HJ, Leichman CG, Danenberg KD, et al. Thymidylate synthase mRNA level in adenocarcinoma of the stomach: a predictor for primary tumor response and overall survival. J Clin Oncol 14: 176-182, 1996.

22. Hirokoshi T, Danenberg KD, Thomas H. Quantitation of thymidylate synthase, dihydrofolate reductase, and DT-diaphorase gene expression in human tumors using the polymerase chain reaction. Cancer Res 52: 108-116, 1992.

23. Takamura M, Nio Y, Yamasawa K, Dong M, Yamaguchi K, Itakura M. Implication of thymidylate synthase in the outcome of patients with invasive ductal carcinoma of the pancreas and efficacy of adjuvant chemotherapy using 5-fluorouracil or its derivatives. Anticancer Drugs 13: 75-85, 2002.

24. Hu YC, Komorowski RA, Graewin S, et al. Thymidylate synthase 
expression predicts the response to 5-fluorouracil-based adjuvant therapy in pancreatic cancer. Clin Cancer Res 9: 4165-4171, 2003.

25. Formentini A, Sander S, Denzer S, Straeter J, Henne-Bruns D, Kornmann M. Thymidylate synthase expression in resectable and unresectable pancreatic cancer: role as predictive or prognostic marker? Int J Colorectal Dis 22: 49-55, 2007.

26. Komori S, Osada S, Mori R, et al. Contribution of thymidylate synthase to gemcitabine therapy for advanced pancreatic cancer. Pancreas 39: 1284-1292, 2010.

27. Kondo N, Murakami Y, Uemura K, et al. Prognostic impact of dihydropyrimidine dehydrogenase expression on pancreatic adenocarcinoma patients treated with S-1-based adjuvant chemotherapy after surgical resection. J Surg Oncol 104: 146-154, 2011.

28. van der Zee JA, van Eijck $\mathrm{CH}$, Hop WC, et al. Expression and prognostic significance of thymidylate synthase (TS) in pancreatic head and periampullary cancer. Eur J Surg Oncol 38: 1058-1064, 2012.

29. Fukui Y, Oka T, Nagayama S, Danenberg PV, Danenberg KD, Fukushima M. Thymidylate synthase, dihydropyrimidine dehydrogenase, orotate phosphoribosyltransferase mRNA and protein expression levels in solid tumors in large scale population analysis. Int J Mol Med 22: 709-716, 2008.

30. Valla DC, Cazals-Hatem D. Sinusoidal obstruction syndrome. Clin Res Hepatol Gastroenterol 40: 378-385, 2016.

31. Fernandez FG, Ritter J, Goodwin JW, Linehan DC, Hawkins WG, Strasberg SM. Effect of steatohepatitis associated with irinotecan or oxaliplatin pretreatment on resectability of hepatic colorectal metastases. J Am Coll Surg 200: 845-853, 2005.

32. Baba M, Shima $T$, Tanaka $T$, et al. A case of allergic liver injury induced by tegafur. J Gastroenterol 29: 88-92, 1994.
33. Maruyama S, Hirayama C, Abe J, Tanaka J, Matsui K. Chronic active hepatitis and liver cirrhosis in association with combined tamoxifen/tegafur adjuvant therapy. Dig Dis Sci 40: 2602-2607, 1995.

34. Kobayashi F, Ikeda T, Sakamoto N, et al. Severe chronic active hepatitis induced by UFTR containing tegafur and uracil. Dig Dis Sci 40: 2434-2437, 1995.

35. Matsumoto M, Nakao K, Matsumoto $\mathrm{H}$, et al. Chronic liver failure induced by long-term administration of tegafur: a case report. Hepatogastroenterology 45: 2372-2375, 1998.

36. Suou T, Tanaka K, Okano J, et al. A case with hepatic fibrosis showing ascites and esophageal varices induced by oral UFT(R) administration. Hepatol Res 22: 161-165, 2002.

37. Honda S, Sawada K, Hasebe T, Nakajima S, Fujiya M, Okumura T. Tegafur-uracil-induced rapid development of advanced hepatic fibrosis. World J Gastroenterol 23: 5823-5828, 2017.

38. Colon-Otero G, Malkasian GD, Edmonson JH. Secondary myelodysplasia and acute leukemia following carboplatin-containing combination chemotherapy for ovarian cancer. J Natl Cancer Inst 85: 1858-1860, 1993.

39. Seymour JF, Juneja SK, Campbell LJ, Ellims PH, Estey EH, Prince HM. Secondary acute myeloid leukemia with inv(16): report of two cases following paclitaxel-containing chemotherapy and review of the role of intensified ara-C therapy. Leukemia 13: 1735-1740, 1999.

The Internal Medicine is an Open Access journal distributed under the Creative Commons Attribution-NonCommercial-NoDerivatives 4.0 International License. To view the details of this license, please visit (https://creativecommons.org/licenses/ by-nc-nd/4.0/).

(C) 2018 The Japanese Society of Internal Medicine Intern Med 57: 3529-3535, 2018 